\title{
ESPECTROS DO VIVENTE NA BANDA DESENHADA
}

\author{
SPECTRA OF THE LIVING IN COMICS
}

PEDRO MOURA*

pedrovmoura@gmail.com

\begin{abstract}
A banda desenhada, enquanto parte do discurso público, e através da sua variedade material e de géneros, proporciona um grande número de exemplos de narrativas nas quais se resubjectiviza $o$ "outro" liminar, compreendido então como tendo um papel activo na força de vida de todo o universo. Este artigo traça uma visão introdutória sobre essa mesma variedade, desenhando um espectro que revela uma cada vez maior consideração de agentes do sensível.
\end{abstract}

Palavras-Chave: banda desenhada; pós-humanismo; agência não-humana; distribuição do sensível; vivente; desterritorialização.

Comics are a very active part of public discourse. Due to its genre and material variety, one can find many examples of narratives that attempt a resubjectification of the ultime "other", with an active role in the holistic lifeforce of the universe. The present paper draws an introductory perspective upon such variety of approaches along a spectrum, towards an ever more encompassing consideration of sensible agents.

Keywords: comics; posthumanism; non-human agency; distribution of the sensible; living; deterritorialization.

Data de receção: 2020-04-25

Data de aceitação: 2020-09-01

DOI: $10.21814 / 2 i .2505$

\footnotetext{
* Investigador independente, doutor pela Universidade Católica de Lovaina, crítico de banda desenhada, Lisboa, Portugal. ORCID: 0000-0002-8997-3639
} 
Na proporção em que nos isolámos numa lógica sobrevivencial exclusiva, e nela nos tomámos como sujeitos únicos no mundo, dessubjectivámos tudo o resto, inactivámos todos os "outros" do mundo, e perdemos o fio das relações com tudo o mais no mundo e com o próprio mundo

- André Barata

Qualquer discussão que implique a noção do além do humano está desde logo - o repetido immer schon, always already, toujours déjà - num contexto interdisciplinar, abrangendo processos, instrumentos, resultados e até aplicabilidades interdisciplinares.

O presente artigo é escrito por alguém cujo campo de trabalho não é, de todo, o póshumano, ou sequer qualquer um dos pós-humanismos, tema do presente número desta publicação. Não foi sem temeridade que aceitei o grato e honroso convite estendido, aqui estruturado num curto texto. Escudo-me, todavia, ao querer acreditar poder contribuir como um guia pelos bosques do território da banda desenhada.

Apesar dos discursos aparentemente conciliadores e de braços abertos à entrada da banda desenhada no mundo académico e na cidade das artes nos presentes dias, no nosso país, a desconfiança não se dissipou por completo, e haverá mais mal-entendidos e preconceitos do que uma compreensão ampla da diversidade de trabalhos, linguagens e estratégias poéticas desta disciplina criativa, assim como do conhecimento secundário que tem sido produzido, incrementalmente, nas últimas décadas. Esta disciplina artística, com uma poética autónoma e própria, tendo desenvolvido nas últimas décadas um verdadeiro corpus de Estudos de Banda Desenhada, tem convidado à produção de abordagens semióticas, fenomenológicas, estruturais e estéticas com todo um instrumentário e história particulares e importa compreender a forma como se tem respondido aos seus desafios, não somente com uma contínua comparação desequilibrada com outras áreas artísticas, mas no seio da sua produção. O presente artigo focar-se-á tãosomente no tema presente, procurando entender como a banda desenhada tem tentado contrariar aquela "lógica sobrevivencial exclusiva" de que o filósofo português André Barata menciona na epígrafe, procurando não "dessubjectivar" mas "subjectivar", não "inactivar" mas "activar" os "outros" do mundo (Barata, 2018, pp. 15-16), inclusive animais, vegetais, minerais e fenómenos físicos com os quais partilhamos circunstâncias de existência e mesmo vivência.

A banda desenhada, construção poética humana, tem sido um palco privilegiado, em termos históricos, para explorações de fantasia, na qual, sem grande alcance analítico, incluiria a ficção científica, o fantástico, o maravilhoso, em suma, géneros que se afastam de uma suposta regra de ouro realista da norma literária vigente. Tais géneros não devem ser menosprezados de forma alguma. Bem pelo contrário, há mesmo neles uma valorização fulcral, dado que "a entrega a uma ontologia que é mais prolífica na alocação de possibilidades para a identidade também implica a possibilidade de repensar as relações com outro-da-identidade" (Herman, 2014, p. 137; minha trad., tal como todas citações).

Todavia, não escamoteemos o facto de que a imaginação, "rainha das faculdades" no adágio de Baudelaire, quer no campo da banda desenhada quer noutras artes, tem sido 
confinada a uma mão-cheia de papéis, categorias, balizamentos que a domesticaram. Nem sempre se verifica um maior aprofundamento dos limites de um conceito tal como o da subjectivização do "outro", humano ou não. É possível mesmo que os seus exemplos mais celebrados tenham sido instrumento de confirmação de limitações políticas e de discursos hegemónicos. Mas há textos que têm, precisamente, imaginado a identidade e alteridade do vivo de modos diferentes.

Ao pensarmos as noções do pós-humanismo, pense-se em formas de transcendência maquínica ou espiritual, drástica evolução biológica, transferências ou transições transespécie, não faltarão exemplos de toda uma ménagerie de robôs, andróides, ciborgues, mutantes, homens e mulheres com capacidades animais ou alienígenas de toda a sorte. Não esqueçamos que uma das personagens mais famosas deste território, apesar de em nada dever à filosofia de Nietzsche, tomou o nome de um seu conceito. Apesar das suas capacidades físicas e origem interplanetária, o Super-homem da DC Comics é mais devedor dos "homens fortes" dos circos e da pulp fiction dos anos 1930, do que de uma figura capaz de quebrar as ilusões dos valores morais da sociedade em que se ancorará.

$\mathrm{O}$ meu foco será um conjunto de trabalhos que tentam demonstrar a capacidade de diálogo e interacção de forças entre entidades distintas, mas compreendidas como agentes e participantes fulcrais na esfera do "vivo". Não estou interessado em focar-me somente em narrativas animais, por exemplo, área que tem sido estudada nos últimos anos, distinguindo de maneira produtiva os "animal comics" do género (de humor e formal) "funny animals" ou "bande dessinée animalière", ao ponto de David Herman ter editado um volume exclusivamente dedicado ao tema: Animal Comics. Multispecies Storyworlds in Graphic Narratives (2017). Tampouco focarei narrativas somente de cariz ecológico, sejam estas ficções salvíficas, distópicas, ou abordagens ensaísticas. Como ensina Cary Wolfe, para se ser verdadeiramente pós-humanista, e libertar-nos da canga ou baia antropocêntrica, temos de abandonar os conceitos da própria subjectividade, da personalidade, do Si. Como o próprio Herman afirma, estes “....relatos ficcionais podem actuar como um espaço de trabalho para reconsiderar - criticando ou re-afirmando, desmantelando ou reconstruindo - narrativas sobre si-mesmos-humanos num mundo em que a identidade se estende para além do domínio do humano" (2014, p. 132).

Com efeito, não basta que se construa uma ficção protagonizada por um não-humano ou um supra-humano em aparência para que se esteja a abrir espaço a essas outras experiências. Essa é uma fraca desterritorialização, para empregar uma linguagem cara a Deleuze e Guattari. O antropomorfismo e até mesmo o teriomorfismo, assim como a ciborguização, a mutantização, etc., pode reconduzir tão somente à reterritorialização, quer da representação em si quer do modo de representação ele-mesmo. Vejamos dois brevíssimos exemplos.

Star-Crossed foi uma série limitada de três comic books publicados em 1997, pelo artista Matt Howarth. A protagonista dessa história é Dyltah, uma humana alterada a nível genético permitindo-lhe viver a navegar no espaço sideral, e a qual se apaixona por Saa, um asteróide sentiente. Com quem comunica através de padrões fotónicos. Não nego que haveria aqui desde logo matéria passível de uma análise sob o signo dos termos-chave do nosso assunto, relativo ao pós-humanismo. Afinal, aqui temos uma mulher que abandona a sua cultura e até imperativos biológicos (no sentido mais básico de respirar oxigénio, alimentar-se, necessitar de temperaturas amenas, locomover-se, etc.) em nome de uma experiência extraordinária, assim como uma relação com uma criatura - o uso desta palavra convida a problematizações - alheia à humanidade. Contudo, toda a narrativa, os modos de comunicação, de relação (inclusive "amorosa") e sobretudo de enredo acaba por inscrever Star-Crossed numa série de caminhos bastante normalizados, naturalizados, 
para não dizer até normativos, quer de estruturas de género literário - o drama romântico - quer das estratégias discursivas.
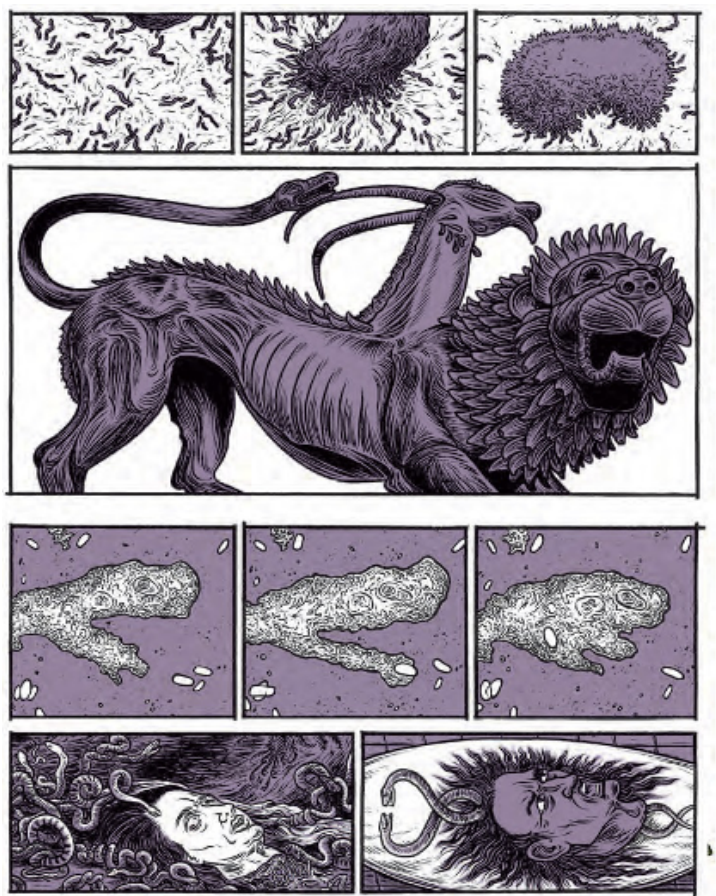

Fig. 1. Jens Harder, Alpha... evolutionäre Bildgeschichten (2009)

Alpha... evolutionäre Bildgeschichten e Beta...civilisations part 1, do artista alemão Jens Harder, são obras voluminosas, com mais de 350 páginas, publicados em língua francesa, e depois alemã, em 2009 e 2014, respectivamente. Com esta série (ao que tudo indica, a continuar), Harder pretenderá criar uma história enciclopédica visual de... tudo. Não se trata apenas de uma história das civilizações humanas, ou da formação geológica do planeta, mas de cumprir uma narrativa cuja abrangência parte do Big Bang à emergência dos mesões e aminoácidos, das primeiras formas unicelulares à evolução das espécies, e todas as tensões civilizacionais humanas. Contudo, e como escrevi numa recensão a um destes volumes, "apesar da ambição, da abertura e da preocupação ontológica da linguagem da própria banda desenhada, há algo de domesticado em Alpha" (Moura, 2016). Com efeito, Harder mescla representações supostamente objectivas das entidades que pretende apresentar - átomos, mitocôndrias, animais, plantas, etc. - com imagens simbólicas de produção humana - de ícones mitológicos aos oriundos da cultura popular, cenas da história da ciência ou da política - criando o que chamei de "metáforas por contiguidade". Mesmo bebendo de vários fundos religiosos, numa hipotética busca pela "universalidade humana", Harder está sempre a seguir os princípios organizativos e discursivos do conhecimento da história do universo tal qual apresentado pela perspectiva lógica e racional da ciência ocidental. Quer as imagens "simbólicas" quer as da "realidade humana", todavia, criam elos de significação que, em última instância, instilam uma subsunção de tudo o que for representado a uma teleologia humana. É o caso de quando a fusão das bactérias no Criptozóico é comparada com a Quimera (Fig. 1), ou quando o desenvolvimento de grandes criaturas marinhas no Cenozóico parece prometer desde logo os futuros murais em Cnossos ou o monumental Moby Dick. Não quero acusar o autor de nenhum fito ulterior, já que os livros são de facto excelentes instrumentos pedagógicos, e estrutural e visualmente fascinantes, merecedores de uma atenção particular. Mas parece-me que Harder, convidando a falar da história de elementos químicos, geológicos, energéticos, animais, vegetais, climatéricos, sempre no interior do trilho da história humana, cumpre um papel negativo em relação àquela pergunta brutal que Anne Simon coloca num dos seus textos: "Qui a dit que le partage engageait systématiquement la réciprocité?" (2017, p. 84).

Realmente, quaisquer processos criativos, ficcionais, artísticos, que dialoguem com o vivo, com o mundo, farão parte desde logo de um programa biopolítico. Numa perspectiva verdadeiramente pós-humanista, talvez não seja suficiente perguntar-nos a que tipo de affordances o humano pode aceder no seu diálogo (quer sob formas 
explorativas quer colaborativas) mas abandonar essa teleologia humana. Logo, para esse propósito deveremos interrogar obras na medida em que procuram uma administração do vivente para além do calculismo ou utilitarismo humanos (aceitando, claro, que qualquer "obra" é criada pelo humano):

Para além da origem comum do vivente, que logo à partida inscreve o humano num mundo e num espaço partilhados, coloca-se igualmente a questão da ligação entre a animalidade e o político, na qual os animais continuam a definir, quer por reflexo quer por confronto, aquilo que o humano continua a acreditar ser-lhe particular (a polis, a linguagem, a cultura, a história, o fantasma...) (Mairesse \& Simon, 2011, p. 4).

Indo para além do animal, abarcando o vegetal e até o mineral, a acção crucial é a ligação com o político, numa acepção como a de Jacques Rancière, a de "distribuição do sensível", da condição de possibilidade de participar neste diálogo igualitário e abrangente (1995).

Daí que as ficções antropomórficas - seja de protozoários, patos ou asteróides - não sejam necessariamente uma nova conquista do sensível, já que tão-somente alimentam preocupações já/ainda humanas. Devemos ter em mente o que Thomas Lemke escreve, ao discutir a noção de biopolítico: "A instrumentalização da vida está intimamente associada à sua capitalização" (2013, p. 6).

Essa é uma lógica a evitar. É para esse outro sentido que estas ficções - no seu sentido etimológico de "moldado", não necessariamente na sua acepção de categoria literária podem contribuir. "É importante que histórias estão a contar histórias, que conceitos estão a pensar conceitos"... (Haraway, 2015, p. 160).

O primeiro exemplo próximo do território de que queremos dar conta é uma série particularmente convencional no que diz respeito à sua estruturação narrativa e gráfica. Convencional, do ponto de vista analítico, já que historicamente The Saga of the Swamp Thing, a qual em 1984 passou para as mãos do influente argumentista Alan Moore e os seus vários colaboradores artistas, como Stephen Bissette, John Totleben, entre outros, foi de uma diferenciação e impacto extremos na exploração do género, da política, da ecologia, da sexualidade, no seio da dita banda desenhada mainstream norte-americana da sua era, por várias razões, que foram já estudadas de modo cabal (Round, 2014).

A personagem Swamp Thing, ou Monstro do Pântano, foi criada em 1971 pelo escritor Len Wein e o artista Bernie Wrightson, tratando-se de um cientista chamado Alec Holland transformado numa criatura fantástica de aspecto vegetal, após um tipificado acidente envolvendo químicos misteriosos. Holland estudava uma fórmula biorestaurativa para resolver problemas de escassez de alimentos quando é morto por uma explosão. O seu corpo fica coberto com essa fórmula, cai nos pântanos e quando se reergue, é agora um monstro humanóide coberto de matéria vegetal e com as expectáveis extraordinárias capacidades físicas que o lançarão numa série de aventuras fantásticas, sobrenaturais e superhumanas, combatendo outros monstros. Estes, claro está, "maus", na também típica natureza maniqueísta do género de super-heróis, nos quais liminarmente se inscrevia.

A transformação que Moore providencia sobre esta personagem é, usando a palavra na sua plena acepção, radical. Simplificando toda a complexa saga (coligida em oito volumes a partir de 2012), bastará afirmar por agora que o Monstro do Pântano não é, descobre-se, o humano Holland transformado num monstro de aspecto vegetal mas antes um aglomerado de plantas transformado pela fórmula e que, no diálogo dos choques - da morte do homem e da alteração das plantas - acaba por mimetizar a consciência do humano. Moore inverte, portanto, a transformação. Não é um homem que pensa ser uma 
planta, mas uma planta que pensa ser um homem, para parafrasear o que diz uma personagem na narrativa.

Esta descoberta altera todo o papel da personagem, as suas características e capacidades físicas e anímicas, assim como o seu posicionamento no mundo diegético que, entretanto, se tecerá. De um género clássico de terror, Moore e os seus artistas passam a explorar o que um ente vegetal vai experienciar na sua vida, ainda que, num momento inicial, sempre em mimese parcial de uma vida humana, sobretudo na sua relação com outras personagens humanas, meta-humanas ou monstruosas. Ao longo da série, que se estenderia durante cerca de cinco anos, verificar-se-ia uma contínua expansão das capacidades de contacto do Monstro do Pântano com um mundo cada vez maior. Aprendemos desde logo que, enquanto parte do mundo vegetal, esta personagem está em permanente contacto com o que ele chama de "o Verde", descritível como uma rede neuronal espalhada por todo o planeta unindo toda e qualquer espécie de flora.

$\mathrm{O}$ que Moore cria, então, de uma maneira subtil, paulatina e elegante - de que não poderei dar conta nestes resumos deselegantes -, mesmo na ausência, no fundo, de um ser humano conduzindo a personagem, na diegese, é aquilo que Anne Simon chamou de "uma operação de desorientação de si próprio", um "antropomorfismo heurístico".

Se numa primeira fase o Monstro do Pântano atravessa inúmeros choques e aprendizagens lentas e dolorosas, a sua compreensão de si mesmo como uma entidade elemental permitir-lhe-á contactos (kinships, no modo como Donna Haraway emprega a palavra) cada vez mais incríveis: é capaz de viajar pelo Verde e reconstituir-se em qualquer parte do mundo onde haja uma planta (o Amazonas, um ramalhete de rosas, um punhado de tabaco, uma monumental sequoia americana, a madeira de uma sala, a flora intestinal), conforme as necessidades e solução da aventura e crise em questão, reinventando-se conforme o clima ou a flora local, é capaz de reproduzir corpos múltiplos e simultâneos, e chegar a dimensões fora do alcance humano. Chega a aprender, aliás, que não é ele senão o último avatar de toda uma linhagem de paladinos do Verde (o que constitui um descentramento adicional). O nível de fantasia é ainda exponenciado quando ele é obrigado a viajar até ao submundo dos mortos e depois através do espaço, alterando a sua assinatura bio-eléctrica, que o leva a entrosar-se em floras extraterrestres ou mesmo a tomar formas robóticas, momentaneamente.

David Herman, numa leitura analítica que faz da escritora Thalia Field, identifica três estratégias de criar elos de conexão interdependente entre o humano e o animal (que estendo aqui para o vegetal) analisáveis através da "textura" do trabalho - a suposta identificação da "forma" - e do "tema" ou "tópico" - o suposto "conteúdo". São essas estratégias: um jogo entre registos de discurso; a mistura das perspectivas humana e animal; e a flutuação entre escalas de encontros mútuos $(2016,23)$. Um dos episódios mais celebrados de The Saga of the Swamp Thing é "The Rite of Spring" (o número 35 da série em comic book, coligida em Moore et al., 2014). É necessário precisar que, sendo este um projecto relativamente convencional e comercial, algumas das suas abordagens formais foram surpreendentes e inovadoras nesse campo. Depois de uma longa relação de confiança e amizade entre o Monstro do Pântano e uma mulher humana, Abigail Arcane, o amor instala-se entre os dois, e este episódio demonstra a consumação "carnal", se assim se pode dizer, dessa paixão. Essa união não é, de forma alguma, genital, mas 


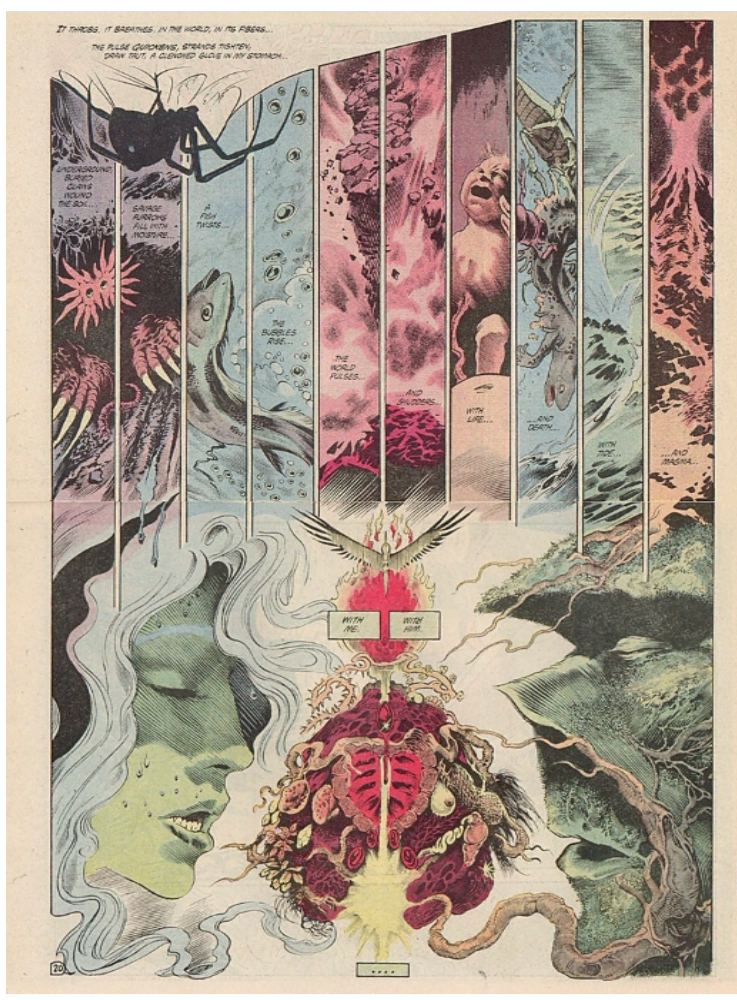

Fig. 2. Alan Moore, Stephen Bissette \& John Totleben, Swampp Thing 34: The Rite of Spring (1985) espiritual e sexual, numa profunda fusão de respirações, ritmos internos, secreções, contacto telepático, que não apaga de todo o fortíssimo erotismo carnal (Fig. 2). Todos aqueles elementos que Herman lista estão aqui explorados de modo provocante - os "registos" na composição experimental das páginas, a fusão das "perspectivas" de Abigail e o Monstro do Pântano, e as "flutuações de escala" à medida que vogam por várias experiências planetárias -, abrindo a uma "outra sensibilidade": o que significa fazer amor com uma e/ou como uma planta? Significa aceder pela pele aos ritmos de todo o planeta e suas criaturas e forças.

Les derniers jours d'un immortel é um livro de banda desenhada francófono, escrito por Fabien Vehlmann e desenhado por Gwen de Bonneval, publicado em 2010. Superficialmente, é uma novela policial-diplomática num contexto de ficção científica: num futuro distante, Elijah, da Polícia Filosófica, tem de compreender um crime cometido há séculos e que opõe duas espécies não-humanas. Polícia-psicológico, a especialização de Elijah é perceber como gerir a alteridade - física, fisiológica, cultural, comunicativa - entre tantas espécies diferentes de quadrantes distintos do universo. A esmagadora maioria dos problemas nasce da incompreensão mútua, e é esse o papel da diplomacia. A segunda linha narrativa desta novela é o facto de que os humanos, neste tempo, são praticamente imortais, podendo transferir as suas consciências para outros corpos (a que chamam "ecos") em caso de necessidade. Um amigo de Elijah, contudo, decide não se transferir de novo, terminando cabalmente a sua existência, o que lança o protagonista numa interrogação profunda. Essa situação, tal como os processos de transferência dos novos corpos, levanta sérias questões sobre o papel da memória na construção do Si humano. Logo, a investigação de Elijah em torno da identidade/alteridade das outras espécies extraterrestres - particularmente estranhas vai espelhar-se na que faz de si mesmo, tecendo uma investigação mais ontológica que policial do que faz, de nós, humanos e, dos outros, não-humanos. Se Ellijah, dada a sua cultura, seguia um caminho tranquilo, balizado, e racional, sempre feito de compromissos mornos, é graças a esta crise que acaba por ultrapassar todos os limites das suas categorias - linguísticas, físicas, cognitivas e existenciais. Apesar desta minha próxima frase ser de um delicodoce horrendo, a lição de Derniers jours é a de que é através do reconhecimento ou compreensão de nós mesmos no outro - seja um amigo humano seja um interlocutor alienígena - que nos construímos. Ou também, é na limitação própria do humano que somos mais humanos.

Se de entre os fitos possíveis da arte se encontra o de alterar modos convencionais de pensar, categorizar e representar, ou como escreve ainda Herman, "os padrões de atribuição empregues em narrativas específicas podem reciprocamente afectar e potencialmente recalibrar assunções normativas sobre espécies de mentes" (2016, p.5), este livro cumpre tal fito. 
Do contacto à escala planetária do Monstro do Pântano à relação sexual-vegetal e a comunicação inter-espécie de Elijah, chegamos agora a uma relação fusional mágica. L'organisme, da artista argentina Natalie Novia (publicado em França em 2018), é um pequeno livro, sem texto, e com uma abordagem vincadamente experimental, de narrativa vaga. A narrativa parece dar conta de uma mulher e de um cão ou cadela que, um dia, são visitados por uma criatura estranha - que tanto pode ser entendida como extraterrestre, como delírio onírico, como até mesmo entidade demoníaca. Esta visita desencadeia uma série de metamorfoses e fusões entre os corpos das personagens, que culminará com uma pequena estranha viagem até um bosque.

O livro inicia-se com uma cena demonstrando a relação íntima entre o cão e a mulher, algo que todos os que vivem com animais domésticos poderão reconhecer: a coabitação e reciprocidade de partilhar a cama, estarem anichados no sofá, da mulher esfregar os pés na barriga do canino, etc. Mas há pequenas pistas que apontam a algo mais fusional, ora pela coincidência - como a caneca que a mulher usa para beber café, a qual tem um cão impresso e a cauda a fazer de pega - ora pelas especificidades formais da banda desenhada - em que as vinhetas, cada uma delas um fragmento da realidade e mostrando uma "vista" diferente da cena, estão colocadas uma sobre a outra de tal maneira que vemos um corpo composto por pernas humanas e corpo de cão. Mas após o surgimento da tal criatura, os

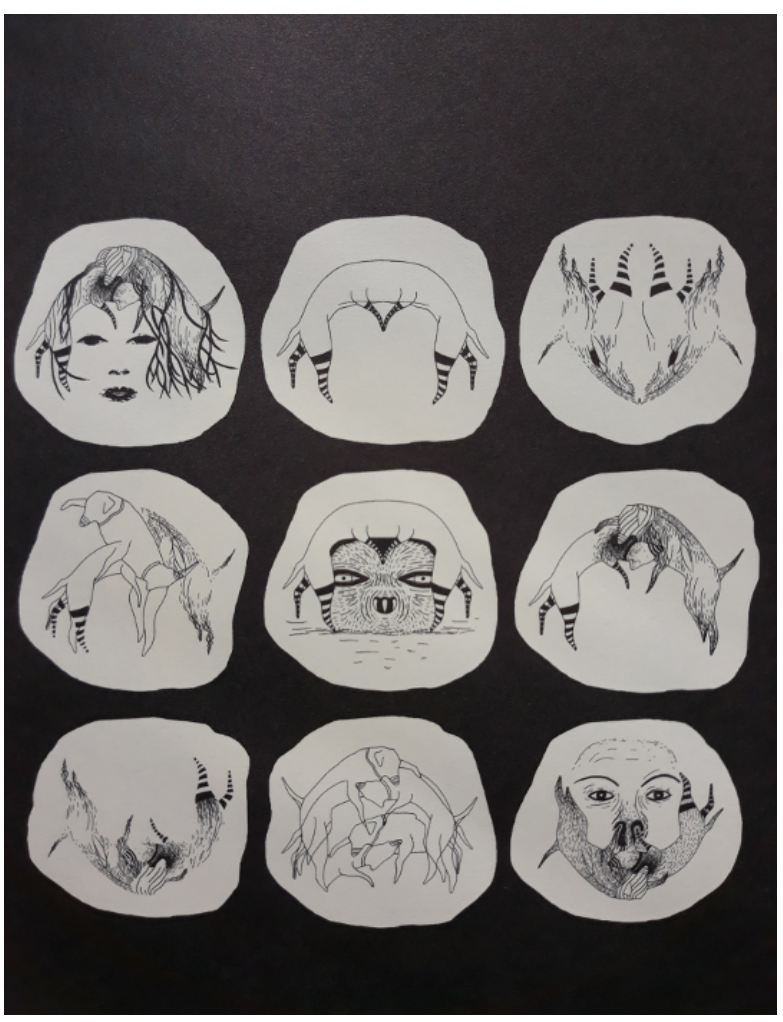

compósitos, apenas prometidos, aumentam de frequência e natureza (Fig. 3), permitindo-nos pensar que talvez estejamos perante uma ilustração do que Deleuze e Guattari chamaram de "devir": não um acto finalizado de transformação, de passagem cabal de uma estrutura objectiva (a de "humano") a outra ("a de "cão"), mas antes uma incessante fluidez entre ambas. Não se trata da transformação, ocorrida de facto na diegese, e parte do seu maravilhoso, do Monstro do Pântano. No caso do livro de Novia, não há uma naturalização ou reterritorialização assegurada pela diegese. Mais, esta fluidez vai mesmo contaminar os espaços circundantes, e mimar o cenário vegetal do espaço que ocupam. É como se a tal criatura reforçasse aquela fusão que já estava prometida na intimidade diária.

Fig. 3. Natalia Novia, L'organisme (2018)

Haveria outros pormenores a discutir, decerto, mas permitam-me saltar para o "fim". Depois de enterrarem ritualmente a criatura, a mulher e o cão retornam aos seus corpos normais e afastam-se. A mulher caminha nua. É claro que poderia escrever que também o cão está nu, mas o cão está sempre "nu". O que ocorre nesta brevíssima cena é que a nudez não-sexualizada da mulher é reveladora do elo, que sempre ali esteve, entre ela e o cão, enquanto duas formas na sua plena condição de vivas e biológicas. Socorrendo-me de novo de David Herman, num momento em que cita a ecofeminista Val Plumwood, este livro tematiza o seu apelo a uma "narrativa transformada do si que coloque em 
primeiro plano 'a própria animalidade e vulnerabilidade ecológica' dos humanos" (2016, p.22). O "organismo" do título de Novia não é apenas a criatura fantástica que traz a disrupção à normalidade, o que seria uma interpretação pobre. Bem pelo contrário, é o ponto de encontro que ela proporciona à relação que já lá estava, e é confirmada no caleidoscópio de fusões que ocupa o livro. Todos são organismos.

O último exemplo não envolve, em rigor, quaisquer organismos.

L'année de la comète é um álbum volumoso, de grande formato, criado por Clément Vuiller, e que relança a relação material da banda desenhada quer com áreas contíguas, como as do álbum ilustrado para a infância, quer com pontos da sua origem multíplice, através dos luxuosos álbuns de imagens do século XIX.

Se narrativa há, ei-la. Um cometa passa ao largo de um planeta. Troços dele caiem na superfície, e a sua própria passagem traz consequências dramáticas. A sua força gravitacional provoca avalanches, erupções vulcânicas, nebulosidades movediças, maremotos e tempestades eléctricas, as quais por sua vez levam a derrocadas e movimentos tectónicos e geológicos. Água termal e lava são despedidas com ímpeto no ar, assim como se dão quedas de fragmentos do cometa que provocam deflagrações, algumas atingindo proporções dantescas e formas semi-animais. Uma vegetação rica nascida dos movimentos vulcânicos explode em formas e cores intensas. O cometa passa (Fig. 4).

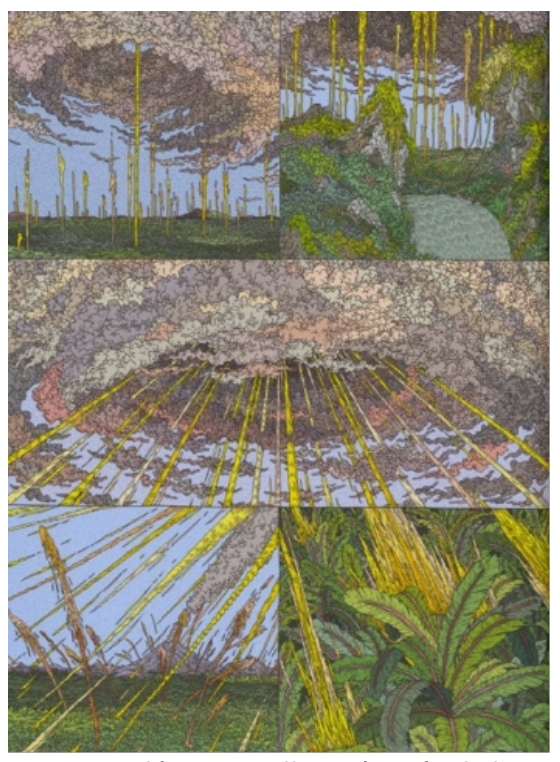

Fig. 4. Clément Vuillier, L'année de la comète (2018)

L'année de la comète não é um livro de personagens, mas é de agentes. Poderíamos dizer que não é de sujeitos, mas de predicados, de acções, de verbos. Tal como Jean-Christophe Bailly quer que os verbos tenham surgido bem antes dos nomes na emergência da fala humana (2011): “(...) com os nomes, estamos no regime do índice, da lista [;] os verbos (...) regozijam-se na natureza" (2011, p.108). Neste livro, poderíamos simplificar com a formulação seguinte: não sei o que se passa, mas qualquer coisa passa, qualquer coisa se passa.

Regressemos a Bailly. Escreve ele: "Há, para cada animal, como que uma oscilação entre uma espécie de compactididade e uma inclinação à evanescência" e "É nessa oscilação que se encontra a marca do vivo" (2011, p.113). Ora, sendo a banda desenhada um modo de expressão cuja estrutura vive precisamente numa tensão entre desenhos num permanente desequilíbrio, em que temos a presença de vários desenhos estáticos, como as suas composições próprias, valências singulares e analisáveis, articuladas entre si na sua multiplicidade (Groensteen, 1999), para que depois possam desaparecer no fluxo contínuo da leitura, no mel da narração, há a possibilidade, não tanto de podermos dizer um daqueles disparates absolutos de que "esta arte é mais apropriada a isto ou aquilo", mas pelo menos de encontrar uma vibração paralela na banda desenhada, adequada a espelhar essa outra oscilação.

Apesar de não existir qualquer ser humano no livro de Vuiller - com a excepção daquele que o criou e daqueles que o lêem, o que não é de somenos - ele contribui, na sua narrativa mineral, cósmica, geológica, energética, para novos modos de subjetivizar e activar o outro não-humano, empregando os termos de André Barata, mas ao mesmo 
tempo resubjectivizar, de outra maneira, o próprio humano. Permitindo-me uma última citação de Herman, de quem tanto me socorri neste artigo, "[e]stas novas narrativas podem ser consideradas mais sustentáveis porque reintegram a identidade (self) humana numa comunidade bem mais alargada de identidades do que aquela reconhecida por normas dominantes das esferas do científico, social, legal e moral" (2014, p. 133).

Abríssemos aqui o campo de exploração para outros textos de banda desenhada experimental - desde banda desenhada abstracta a certos projectos de colagem autofágica e autotélica, intersecções de instrumentos de comunicação visual científica na banda desenhada, etc. - e poderíamos chegar a fitos ainda mais ambiciosos nesta abertura do espaço político do vivente.

Esperamos, em conclusão, que este brevíssimo espectro da banda desenhada, sem hierarquias entre o comercial e o experimental, para públicos alargados ou de nicho, bebendo sem pejo de géneros consolidados ou trilhando novos sulcos, e estes agentes, de aglomerados vegetais fantásticos de consciência expansiva a hierogamias humanoanimais sob o signo do insólito, de diplomacias alienígenas a diálogos cósmicogeológicos, possam demonstrar a existência de alguns espaços de possível reimaginação da zoé, a vida nua e comum, em novas bios, vidas politizadas e expressas. Se nos quadradinhos, nas vinhetas, se pode encerrar um zoo, é na sua leitura que se articula o vivo.

\section{REFERÊNCIAS}

Bailly, J.-C. (2011). Les animaux conjuguent les verbes en silence. L'Ésprit Createur, 51(4), 106114.

Barata, A. (2018). E se parássemos de sobreviver? Pequeno livro para pensar e agir contra a ditadura do tempo. Lisboa: Documenta.

Groensteen, T. (1999). Système de la bande dessinée. Paris : Presses Universitaires de France.

Haraway, D. (2015). Anthropocene, capitalocene, plantationocene, chthulucene: Making Kin. Environmental Humanities, 6, 159-165.

Harder, J. (2010). Alpha ... evolutionäre Bildgeschichten. Hamburgo: Carlsen Verlag.

Harder, J. (2014). Beta...civilisations part 1. Hamburgo: Carlsen Verlag.

Herman, D. (2011). Storyworld/Umwelt: Nonhuman experiences in graphic narratives. SubStance, 124, 40(1), 156-181.

Herman, D. (2014). Narratology beyond the Human. DIEGESIS. Interdisziplinäres E-Journal für Erzählforschung / Interdisciplinary E-Journal for Narrative Research 3(2), 131-143.

Herman, D. (2016). Hermeneutics beyond the species boundary: Explanation and understanding in animal narratives. Storyworlds: A Journal of Narrative Studies, 8(1), 1-30.

Herman, D. (Ed.) (2017). Animal comics: Multispecies storyworlds in graphic narratives. Londres: Bloomsbury.

Howarth, M. (1997). Star Crossed 1-3. Nova Iorque: DC Comics. 
Lemke, T. (2013). Biopolitics and beyond: On the reception of a vital Foucauldian. Disponível em https://transmediji.files.wordpress.com/2013/03/biopolitics_and_beyond thomaslemke.pdf

Moore, A., Bissette, S., \& Totleben, J. (2012). The saga of the swamp thing: Book one. DC Comics: Nova Iorque.

Moore, A., Bissette, S., \& Totleben, J. (2014). The saga of the swamp thing: Book two. Nova Iorque: DC Comics.

Moura, P. (2016). s/tít. Disponível em http://lerbd.blogspot.com/2016/04/alpha-directions-jensharder.html

Novia, N. (2018). L'organisme. Paris: Insula.

Rancière, J. (1995). La mésentente: Politique et philosophie. Paris: Galilée.

Round, J. (2014). Gothic in comics and graphic novels: A critical approach. Jefferson NC: McFarland.

Simon, A. \& Mairesse, A. (2011). Introduction. L'Esprit Créateur, 51(4), 1-5.

Simon, A. (2017). Du peuplement animal au naufrage de l'Arche : La littérature entre zoopoétique et zoopoéthique. L'Esprit Créateur 57(1), 83-98.

Vehlmann, F. \& De Bonneval, G. (2013). Les derniers jours d'un immortel. Paris : Futuropolis.

Vuiller, C. (2019). L'année de la comète. Estrasburgo: Éditions 2024.

(O autor usa a antiga ortografia.) 